\title{
Investigations of Non-Edible Seeds Oils in Comparison with Soybean Benchmark for Production of Biodiesel
}

Kenneth C. Okafor ${ }^{1}$, Musa B. Danjaji ${ }^{1}$, Martin Figura ${ }^{1}$ and Valerie Nwajeyi ${ }^{2 *}$

${ }^{1}$ Department of Civil \& Mechanical Engineering Technology \& Nuclear Engineering, South Carolina State University, Orangeburg, SC 29117, USA ${ }^{2}$ University of Michigan, 701 Tappan Street, Ann Arbor, MI 48109, USA

\section{Abstract}

The desire to reduce green-house gases due to excessive use of fossil fuels for energy production is a major stimulant for alternative clean sources of energy. One of these alternative sources is biodiesel with vegetable oil as a component. However, soybean oil, which is a major food condiment is the major vegetable oil used in the USA. The present study seeks to explore suitable and sustainable sources of oil from non-edible seed plants that are indigenous to the state of South Carolina.

Seed plants were obtained from the wild or purchased. Comparisons of the yields and other physical and chemical properties were determined and compared to soybean oil as the benchmark.

All the seeds in this study underwent the same processes in oil extraction and determination of their properties. The physical and chemical properties determined for all seeds were the oil yield, density and the iodine value.

Most of the oil samples in this study have characteristics that are comparable to those of the Soybean which is the benchmark sample. For example, most of the oil samples produced yields greater than $7 \%$ the yield for the soybean oil. It can also be inferred from this study that any one of the comparable seed plants mentioned above can serve as an alternative feedstock to Soybean in the commercial production of Fatty Acid Methyl Esters (FAME).

\section{Introduction}

The desire to reduce green-house gases due to excessive use of fossil fuels for energy production is a major stimulant for alternative clean sources of energy. Research in alternative energy sources received a major boost with the Energy Policy Act of 2005 [1]. This Act "authorizes loan guarantees for innovative technologies that avoid green-house gases, which might include advanced nuclear reactor designs, such as pebble bed modular reactors (PBMRs) as well as clean coal and renewable energy". The Act stipulated the amount of biofuel that must be mixed with gasoline sold in the United States by the year 2012 in progression. It stipulated 4 billion US gallons $\left(15,000,000 \mathrm{~m}^{3}\right)$ by $2006,6.1$ billion US gallons $\left(23,000,000 \mathrm{~m}^{3}\right)$ by 2009 and 7.5 billion US gallons $\left(28,000,000 \mathrm{~m}^{3}\right)$ by 2012 [2]. Two years later, the Energy Independence and Security Act of 2007 extended the target to 36 billion US gallons $\left(140,000,000 \mathrm{~m}^{3}\right)$ by the year $2022[1,2]$.

Due to these mandates, research activities in alternative energy sources have increased, especially in biodiesel. There are a few reasons for that. For one, the use of biodiesel maintains a balanced carbon cycle since it is based on renewable biological materials. It produces reduced emissions (carbon dioxide, sulfur, aromatic hydrocarbons and soot particles). Also, biodiesel is non-toxic and completely biodegradable and, due to its high flash point, it is of low flammability such that its use is safe and non-hazardous. Furthermore, it provides good lubrication properties, thereby reducing wear and tear on engines $[3,4]$.

Studies in biodiesel have included biodiesel production from plant seeds, Straight Vegetable Oil (SVO) [5], Waste Vegetable Oil (WVO) [6] and oils from algae and cellulosic materials. In the case of SVOs (including plant seed oils) and WVOs, the production method involves the trans-esterification [7] of the triglycerides using methanol or ethanol in the presence of catalysts. However, for algae and cellulosic materials, the production methods are through microbial agents (E. coli). 48109, USA; E-mail: vnwadeyi@umich.edu $351 X / 2019 / 161$ original author and source are credited.

\section{Publication History:}

Received: November 27, 2018

Accepted: January 09, 2019

Published: January 11, 2019

\section{Keywords:}

Biodiesel, Soybean, Fossil fuels, dynamics, Non-edible

the growth of algal feedstock and molecular cloning methods [8] of

Nevertheless, both methods have disadvantages: in the transesterification process, vegetable oil is required in large quantities. Also, the vegetable oil that can be used in biodiesel production may be a staple food for humans, for example the soybean [5-8].

As a result of the above and depending on the vegetable oil used for the production of biodiesel in commercial quantities, it negatively impacts the cost of the oil and its sources (corn, soy- bean, etc) resulting in the scarcity of these food materials creating potential human hardship. Even switching from SVOs to WVOs is unlikely to solve the problem since the production of biodiesel in commercial quantities due to increased demand is expected to outstrip supplies of the WVO resulting in the non-sustainability of the industry.

As a result of the above and depending on the vegetable oil used for the production of biodiesel in commercial quantities, it negatively impacts the cost of the oil and its sources (corn, soy- bean, etc) resulting in the scarcity of these food materials creating potential human hardship. Even switching from SVOs to WVOs is unlikely to solve the problem since the production of biodiesel in commercial quantities due to increased demand is expected to outstrip supplies of the WVO resulting in the non-sustainability of the industry.

"Corresponding Author: Valerie Nwajeyi, University of Michigan, Ann Arbor, MI

Citation: Okafor KC, Danjaji MB, Figura M, Nwajeyi V (2019) Investigations of Non-Edible Seeds Oils in Comparison with Soybean Benchmark for Production of Biodiesel. Int J Earth Environ Sci 4: 161. doi: https://doi.org/10.15344/2456-

Copyright: (c) 2019 Okafor et al. This is an open-access article distributed under the terms of the Creative Commons Attribution License, which permits unrestricted use, distribution, and reproduction in any medium, provided the 
Concerning biodiesel production from the cloning of E. coli, the research in this process is still in its infancy and may not mature into a practical and industrial process for many years because the biodiesel yields in these engineered bacteria is poor. In the studies in Ref. 8, the authors concluded that even though early optimization studies report a Fatty-Acid Ethyl Ester (FAEE) yield of up to 26\%, that E. coli is not ideal for biodiesel production. Firstly, the FAEE biosynthesis was strictly dependent on the supplementation of exogenous fatty acids. Secondly, the biosynthesis process of FAEE optimization in E. coli is relatively slow resulting in low production, according to the authors [8].

More importantly, the process of microbial biosynthesis compared with the trans-esterification of glycerides with alcohols boils down to the exchange of one food staple (oil) with another (sugar) since the bacteria need a sugar medium (food) to function.

In the case of algal feedstock, Ref. 10 states that a comprehensive study was done by the National Renewable Energy Laboratory (NREL). This study was conducted through the Aquatic Species Program (ASP) from 1978 to 1996 . However, there are challenges in the production of algal feedstock. The authors state, "Despite tremendous interest in algal feedstocks for biodiesel, the literature contains relatively few reports of detailed compositional profiles of the triglyceride fractions in algal lipids...for some algal strains, the FA compositional profiles are highly influenced by specific growth conditions such as nutrient levels, temperatures, and light intensities."[10] The above situations create associated difficulties such as not being able to define a single compositional profile for algal-based biodiesel, in contrast to vegetable oil based biodiesel and the inability to identify exact species involved in lipid production.

The present study seeks to explore other suitable and sustainable sources of oil from seed plants that are indigenous to the state of South Carolina. It is anticipated that these alternative sources of oil will not only provide efficient and sustainable sources of oil but will also spur economic growth in terms of agricultural activities in the state.

\section{Selection Process}

A lot of seed plants $[9,10]$ have been investigated and their chemical and physical characteristics [10] have been evaluated. However, most of these plant seeds are not native to South Carolina. In this study, four criteria are established for choosing the plants. The four criteria include that:

1. The plant must be non-edible or a non-staple plant.

2. The plant must be a plant native to South Carolina or the surrounding region.

3. The plant must have a fast maturity rate.

4. It must have a relatively high oil yield.

\section{Methodology}

Based on the first three criteria above, seed plants were obtained from the wild or purchased. Comparisons of yields from the various seed plants are based on 400 gm of seeds. The following non-edible seeds were studied: Black Eyed Susan, Bachelor Button-Cornflower, Wild Sunflower, Lavender, Shasta Daisy, Morning Glory and Purple Coneflower. Included in the seeds study is the edible but non-staple seed, Pecan.
In addition to the above-mentioned seeds, other well studied and characterized seeds were also analyzed as benchmarks in order to provide sources of comparison for the seeds under investigation. These benchmark seeds are the Peanut and Soybean. Also included in the benchmark specimens is ordinary vegetable oil (Crisco Pure Vegetable Oil). All the seeds in this study underwent the same processes in oil extraction and determination of their properties excepting the ordinary vegetable oil which did not need any additional processing.

The physical and chemical properties determined for all seeds were the oil yield, density and the iodine value. The procedures used to obtain the Oils and values found in Table 1 are as shown below:

\section{Oil extraction of oils}

A standardized mass of $400 \mathrm{~g}$ was used for all seeds and the extraction was done using a commercial oil extraction machine (Pure Nature Oil Press). The procedure follows:

1. For each seed, the standard is measured out in a foil pan.

2. The pan and seeds are roasted in an oven at $120 \mathrm{oC}$ for 3 hours.

3. The Extraction machine is turned on for at least 30 minutes (to heat up the extraction element).

4. The seeds are then processed through the extraction machine (oil and seed particles are collected in one can while the solid flake-like residues are collected in another can).

5. The oil is filtered to separate the seed particles from the oil.

6. The filtered oil is poured into a calibrated tube(s) for measurements of mass and volume from which the extraction yield in percent (\%) is calculated as the ratio of the mass of the extracted oil and the standard mass of seeds multiplied by 100 .

\section{Density Measurement}

The density measurement was done using the $10 \mathrm{~mL}$ tubes from step 6 in procedure A-1 and a sensitive measuring scale (can measure as small as $0.0001 \mathrm{~g}$ ) in the following steps:

1. The volume of the filtered oil samples from procedure A-1 is noted.

2. The mass of the filtered oil in the tubes is weighed on the scale and noted $[($ mass of oil + tube $)$-mass of tube $)]$. The mass is noted in grams.

3. The density of the oil sample is then calculated as the ratio of the mass of oil sample and the volume of the sample $\left(\mathrm{g} / \mathrm{cm}^{3}\right)$.

4. Iodine Value Determination (Iodine Number of Oils \& Fatty Acids, Texas Department of Transportation, Tex-809-B, August 1999)

The titration method is used to determine the degree of unsaturation of the fatty acids (triacylglycerides) in the oil samples. The unsaturation of an oil sample is measured as the iodine number, that is, the mass of iodine that can be dissolved in $100 \mathrm{~g}$ of the fatty acid in an oil sample or g-I2/100g-FA. The higher the iodine number of an oil sample, the more unsaturated is its fatty acid.

Reagents needed are: chloroform, iodine, potassium iodide solution, sodium thiosulfate, starch solution, and oil sample (from Fisher Chemical). 
Citation: Okafor KC, Danjaji MB, Figura M, Nwajeyi V (2019) Investigations of Non-Edible Seeds Oils in Comparison with Soybean Benchmark for Production of Biodiesel. Int J Earth Environ Sci 4: 161. doi: https://doi.org/10.15344/2456-351X/2019/161

Page 3 of 4

Pieces of equipment needed are: calibrated metering cylinders, 2 flasks.

Two titrations are required:

a) The first is a blank test (no oil is added).

b) The second is done with the oil sample.

The following are the steps necessary in the determination of the iodine number:

1. Add $20 \mathrm{~mL}$ of chloroform in a $250 \mathrm{~mL}$ iodine flask.

2. Add approximately $0.3 \mathrm{~g}$ of sample oil into the flask (for the blank test, no oil is added).

3. Add $25 \mathrm{~mL}$ of iodine solution in the flask.

4. Leave the flask above with its contents in the dark for one hour.

5. As soon as the flask is retrieved after 1-hour, add $20 \mathrm{~mL}$ of potassium iodide solution and shake well.

6. Gradually titrate sodium thiosulfate into the flask until the solution turns to orange/yellow color (for a better color change indicator, add $2 \mathrm{~mL}$ of starch solution in the flask before starting the titration).

7. Continue the titration started in Step 6 until the solution turns colorless.

8. Record the volume of sodium thiosulfate needed to just turn the solution colorless in Step 7.

9. Determine the Iodine value using the formula:

IODINE VALUE $=\left(127^{\star}(\mathrm{B}-\mathrm{S})^{\star} \mathrm{N}^{\star} 100^{\star} 10-3\right) / \mathrm{moil}$

Where;

B : volume of sodium thiosulfate used for "blank" solution $(\mathrm{mL})$

S: volume of sodium thiosulfate used for "sample oil" solution

$(\mathrm{mL})$

moil: mass of oil sample ( $\mathrm{g}$ )

$\mathrm{N}$ : normality of sodium thiosulfate solution ( $\mathrm{N}=0.1$ usually)

127: value of the equivalent mass of iodine

\section{Results}

Figure 1 shows the extracted oils in graduated tubes from the seed samples. It can be observed that the oil colors range from a bright yellow to brownish yellow representing the variation in the impact of the color on the seed color
It can be observed from Table 1 that the oil yield values range from about 5 to $45 \%$ : the highest yield is for Pecan seeds (45\%), a non-staple food source; the lowest yield is below 5\% for the Purple Coneflower seeds.

The benchmark seeds, Soybean and Peanut have yields of 7 and $34 \%$ respectively. It should be noted that the Soybean seed, which is the main source of triglyceride feedstock in the US for biodiesel production, has a yield of only $7 \%$.

It can also be observed that the density values in Table 1 range from a high of $0.9268 \mathrm{~g} / \mathrm{mL}$ (Lavender seeds) to a low of $0.9038 \mathrm{~g} / \mathrm{mL}$ (Crisco Oil). These values show a variation of $2 \%$. As a result, these density values can be assumed to be the same at approximately $0.9 \mathrm{~g} /$ $\mathrm{mL}$ (to a decimal point).

Table 1 also shows the Iodine Values (IV) for the oil samples. The IV is one of the most important variables measuring the performance of biodiesel fuels (Fatty Acid Methyl Esters or FAMEs)[10]. The suitability of an oil sample in FAME is dependent on the characteristics of the FA contents of the oil. Based on this inference, Ref. 10 concluded that the IV and the viscosity of the FAs in biodiesels are the most

\begin{tabular}{|l|l|l|l|}
\hline seed & Oil Yield (\%) & Density at $67.4^{\circ} \mathrm{F}$ & \\
\hline$(\mathrm{g} / \mathrm{mL})$ & Iodine Value & & 128 \\
\hline $\begin{array}{l}\text { Crisco Pure Vegetable } \\
\text { Oil }\end{array}$ & $\mathrm{n} / \mathrm{a}$ & 0.9038 & 95 \\
\hline Peanut & 34.3 & 0.9056 & 141 \\
\hline Soybean & 7.0 & 0.9115 & 113 \\
\hline Pecan & 45.0 & 0.9157 & 144 \\
\hline Black Eyed Susan & 23 & 0.9213 & 133 \\
\hline $\begin{array}{l}\text { Bachelor Button- } \\
\text { Cornflower }\end{array}$ & 21.5 & 0.9111 & 136 \\
\hline Wild Sunflower & 20.6 & 0.9165 & 193 \\
\hline Lavender & 20.5 & 0.9268 & 135 \\
\hline Shasta Daisy & 9.5 & 0.9171 & 113 \\
\hline Morning Glory & 7.2 & 0.9080 & $\mathrm{n} / \mathrm{a}$ \\
\hline Purple Coneflower & $<5.0$ & $\mathrm{n} / \mathrm{a}$ & \\
\hline
\end{tabular}

Table 1: shows the physical and chemical properties determined for the oils of the sample seeds.

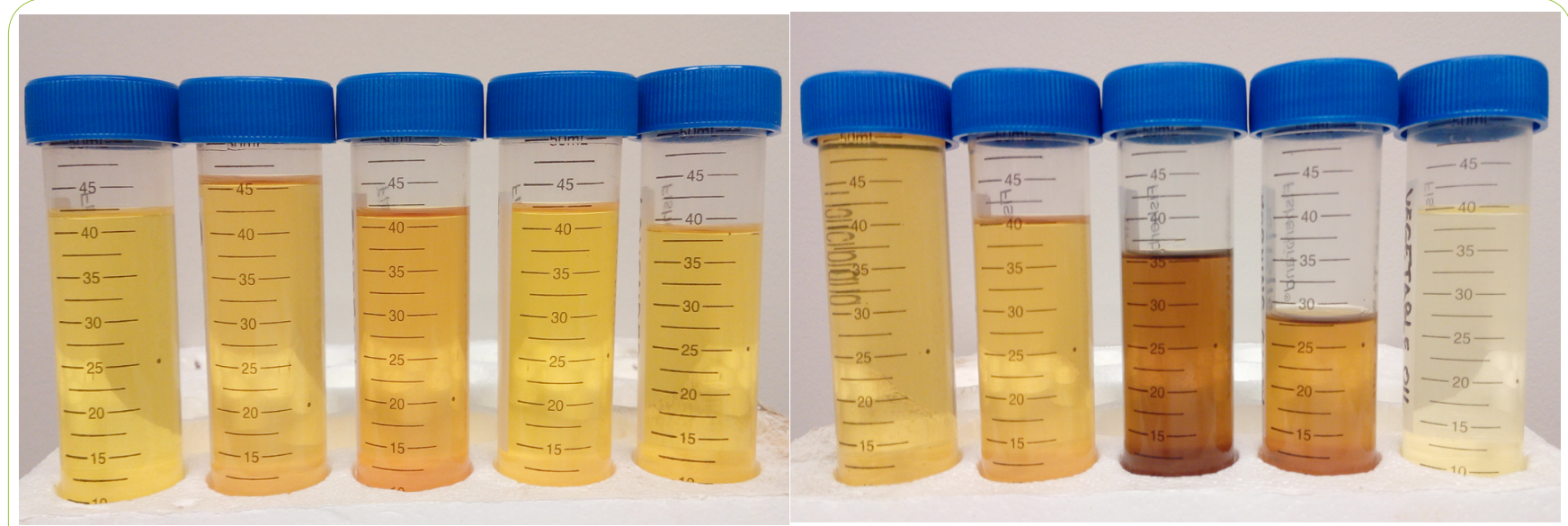

Figure 1: Samples of Extracted Oils from the Seed Samples. 
Citation: Okafor KC, Danjaji MB, Figura M, Nwajeyi V (2019) Investigations of Non-Edible Seeds Oils in Comparison with Soybean Benchmark for Production of Biodiesel. Int J Earth Environ Sci 4: 161. doi: https://doi.org/10.15344/2456-351X/2019/161

Page 4 of 4

important variables in FAME performance even though "it is not possible to define a single composition that is optimum with respect to all important fuel properties...due to opposing effects of certain FAME structural features." The study of Ref. 10 concluded that only the IV and the viscosity have high correlation $(>0.90)$ with the most important factor influencing biodiesel performance. These factors include the Cetane Number, Flash Point, Heating Value, Specific Gravity or Density and Cold Flow Properties (Cloud Point (CP), Pour Point (PP), and Cold Filter Plugging Point (CFPP). However, even though these cold flow properties are important, they are not part of the Standards in the US because these variables can be inferred from other easier measurable variables [10].

Least-square- fit curves were generated in Ref. 10 for those oil variables with high correlation values and plotted. The data for the biodiesel performance variables were obtained from a variety of sources. These fits included the benchmark seed, Soybean.

The plots against the IV show increasing performance values for increasing IVs especially for viscosity, CP, Specific Gravity, Cetane Number and Higher Heating Values. Soybean oil is one of the 12 in the study and from the values in Table 1 the IVs of all the oil samples are unsaturated and are comparable with the Soybean value. Increasing IV values represent highly unsaturated FAs. The biodiesel performance variables that are improved as the IV is increased are the viscosity (lowered), cloud point (lower temperatures), cetane number (lowered) and the heating value.

\section{Observations and Conclusions}

Based on the data in Table 1 and the above considerations, it can be concluded that most of the oil samples in this study have characteristics that are comparable to those of the Soybean which is the benchmark sample. As a result, it can be concluded that all the sample oils in Table 1 with a yield of $7 \%$ or more can be used in the production of biodiesel. These seed plants include Pecan (non-staple), Black Eyed Susan, Bachelor Button-Cornflower, Wild Sunflower, Lavender, Shasta Daisy and Morning Glory, all non-edible plants.

It can also be inferred from this study that any one of the seed plants mentioned above can serve as an alternative feedstock to Soybean in the commercial production of FAME.

Further work in this area will involve a more detailed analysis of the viscosities of these oil samples in order to better characterize their temperature dependence which is a critical factor in the flow and cold flow properties of FAMEs. In addition to investigations of the characteristics of the FAs, those of the FAMEs will also be needed in order to better understand their performance characteristics. Therefore, greater quantities of the oils will be needed for the production of FAME samples.

Also, investigations are on-going to determine other possible nonedible seed plants that can yield appreciable quantities of oil compared to the present feedstock for the production of biodiesel. Further studies may be required to determine the optimum cultivation conditions of these plants and the mechanism for the mass production of the oils in an efficient and economical manner.

\section{Funding}

This material is based upon work that is supported by the National Institute of Food and Agriculture, U. S. Department of Agriculture, Evans-Allen project number SCX-312-05-15.

\section{Competing Interests}

The authors declare that they have no competing interests.

\section{References}

1. Duffield AJ, Collins K (2017) Evolution of Renewable Energy Policy. Choices Magazine.

2. Energy Policy Act of 2005, Pub. L. No. 109-58, 119 Stat. 594 (2005).

3. Janaun J, Ellis N (2010) Perspectives on Biodiesel as a Sustainable Fuel"., Renewable and Sustainable Energy Reviews 14: 1312-1320.

4. Sheehan J, Camobreco V, Duffield J, Graboski M, Shapouri H (2017) An Overview of Biodiesel and Petroleum Diesel Life Cycles. U.S. Department of Agriculture and U.S. Department of Energy.

5. Hellier P, Ladommatos N, Yusaf T (2015) The Influence of Straight Vegetable Oil Fatty Acid Composition on Compression, Ignition, Combustion and Emissions. Fuel 143: 131-143.

6. Refaat AA (2017) Different Techniques for the Production of Biodiesel from Waste Vegetable Oil. International Journal of Environmental Science \& Technology 7: 183-213.

7. Meher L, Vidyasagar D, Naik S (2006) Technical Aspects of Biodiesel Production by Transesterification-A Review. Renewable and Sustainable Energy Reviews 10: 248-268.

8. Kalscheuer R, Stölting T, Steinbüchel A (2006) Eschercha coli Engineered for Fuel Production. Microbiology 152: 2529-2536.

9. Wang R, Hanna MA, Zhou WW, Bhadury PS, Chen Q, et al. (2011) Production and Selected Fuel Properties of Biodiesel from Promising Non-Edible Oils: Euphorbia Lathyris L., Sapium Sebiferum L., and Jatropha Curcas L. Bioresource Technology 102: 1194-1199.

10. Hoekman SK, Broch A, Robbins C, Ceniceros E, Natarajan M, et al. (2012) Review of biodiesel composition, properties, and specifications. Renewable and Sustainable Energy Reviews 16: 143-169. 